\title{
Deep eutectic solvent formed by imidazolium cyanopyrrolide and ethylene glycol for reactive $\mathrm{CO}_{2}$ separations
}

\author{
Yun-Yang Lee, Drace Penley, Aidan Klemm, William Dean, Burcu Gurkan* \\ Department of Chemical and Biomolecular Engineering, Case Western Reserve University, \\ 10900 Euclid Ave, Cleveland, Ohio, 44106
}

\section{Supporting Information}

Number of pages: 16

Number of figures: 9

Number of tables: 7

\section{Materials}

1-Ethyl-3-methyl-imidazolium chloride ([EMIM][CI], 99\%) was purchased from TCl America; 1,2dimethylimidazole, 2-bromoethane, methanol, acetonitrile, ethyl ether, pyrrole 2-carbonitrile (99\%), and amberlite IRN-87 anion exchange resin (AER) were purchased from Alfa Aesar; Ethylene glycol (99.8\%) was purchase from Acros Organics; Chromium acetylacetonate $\left(\mathrm{Cr}(\mathrm{ACAC})_{3}, 97 \%\right)$ was purchase form Millipore-Sigma; DMSO-d $\mathrm{d}_{6}(99.9 \%)$ was purchased from Norell Inc. Amberlite AER was washed by methanol three times and vacuumed dried under room temperature (RT) overnight prior to use, whereas other chemicals were used as received without further purification. Nitrogen ( $\mathrm{N}_{2}$, Ultra High Purity), carbon dioxide $\left(\mathrm{CO}_{2}\right.$, Bone Dry), and helium (He, Ultra High Purity) were purchased from Airgas. Thrift-grade 7" $5 \mathrm{~mm}$ NMR tubes were purchase from DWK Life Science.

\section{IL synthesis and characterization}

1-Ethyl-2,3-dimethyl-imidazolium bromide ([EMMIM][Br]) was synthesized by a Menshutkin reaction. In a $100 \mathrm{ml}$ round bottom flask, 1,2-dimethylimidazole and 2-bromoethane (1.05 eq) were added into acetonitrile, heated, stirrer, and refluxed at $40{ }^{\circ} \mathrm{C}$ under $\mathrm{N}_{2}$ atmosphere for at least 2 days. The white crystals were recovered by a rotary evaporator at $70^{\circ} \mathrm{C}$, purified by an ethyl ether wash to rinse off any unreacted reactants, and dried under vacuum oven at $90^{\circ} \mathrm{C}$. [EMIM][2CNpyr] and [EMMIM][2-CNpyr] were synthesized by anion exchange following the procedure in [Gurkan et al., J. Phys. Chem. Lett. 2010, 1, 24, 3494-3499]. The molecular structure of all samples was characterized by ${ }^{1} \mathrm{H}$ NMR with Bruker Ascend HD 500 MHz NMR; see Figures S1 and S2. The residual chloride or bromide impurity of these samples was tested by silver nitrate with no visual precipitates and were also confirmed to be lower than the detection limit of the combustion ion chromatography, which is $0.25 \%$, by Atlantic Microlab in Norcross, GA. 


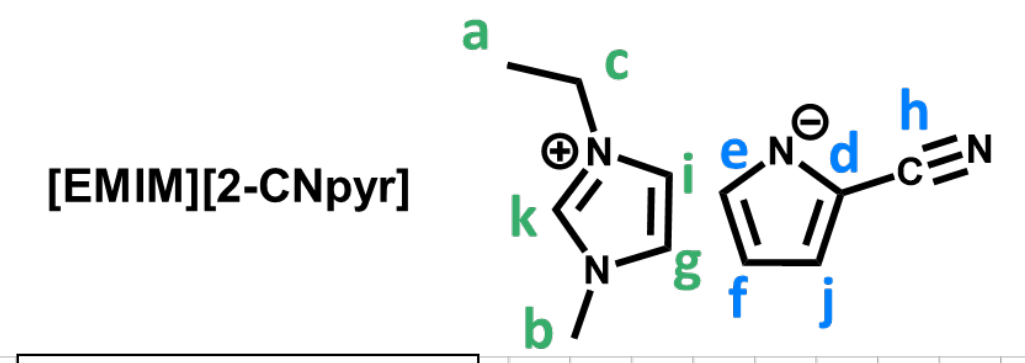

(a) ${ }^{1} \mathrm{H}-\mathrm{NMR} / \mathrm{DMSO}-\mathrm{d}_{6}$

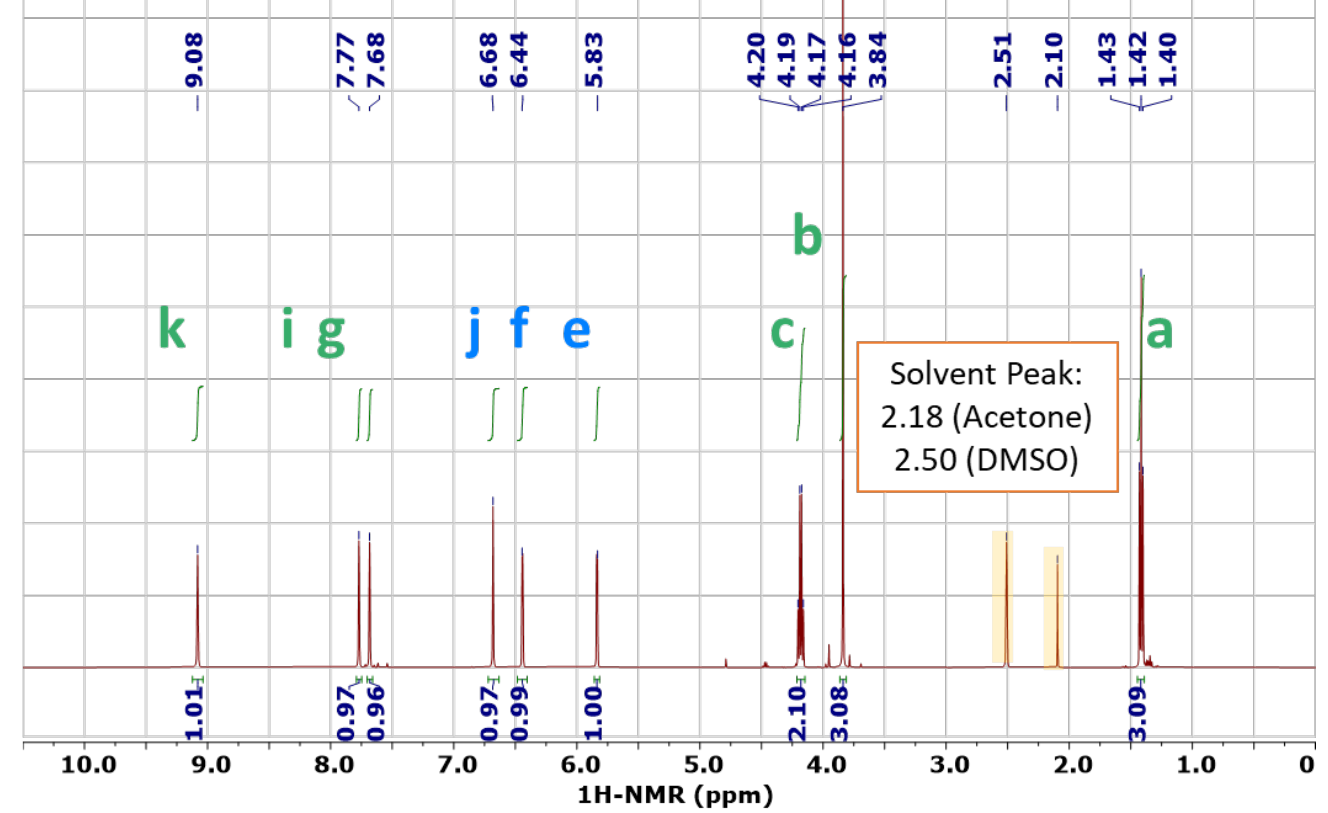

\section{(b) ${ }^{13}$ C-NMR / DMSO-d 6}

กิน

岗
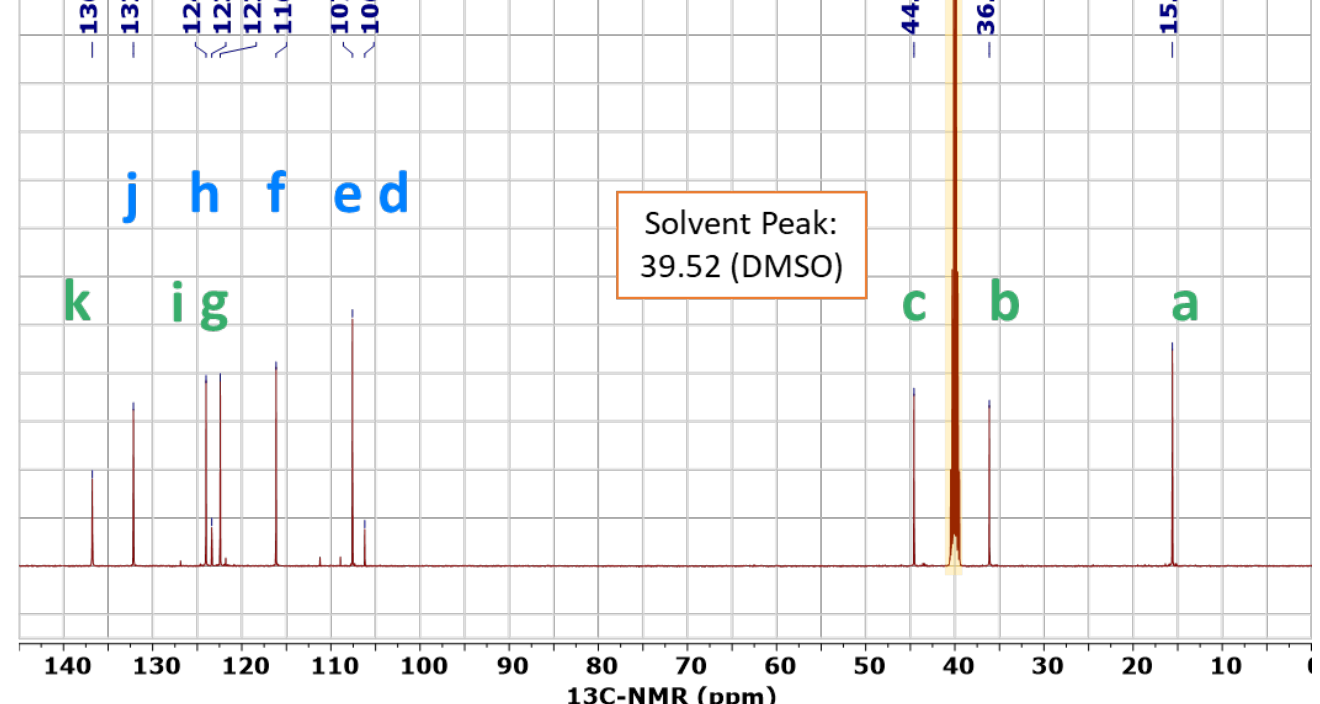

Figure S1. (a) ${ }^{1} \mathrm{H}-\mathrm{NMR}$ and (b) ${ }^{13} \mathrm{C}-\mathrm{NMR}$ of [EMIM][2-CNpyr]. 

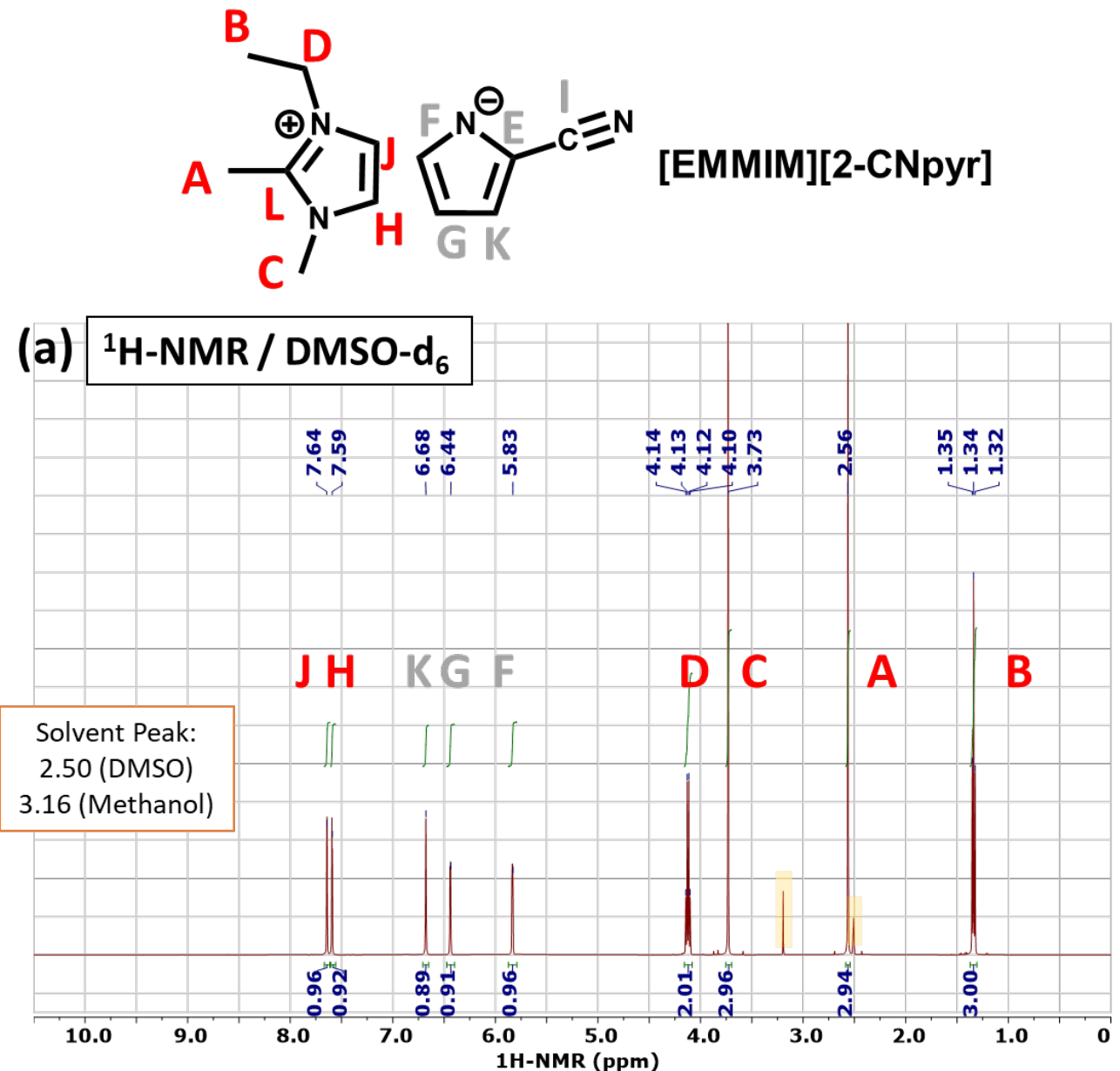

(b) ${ }^{13}$ C-NMR / DMSO-d 6

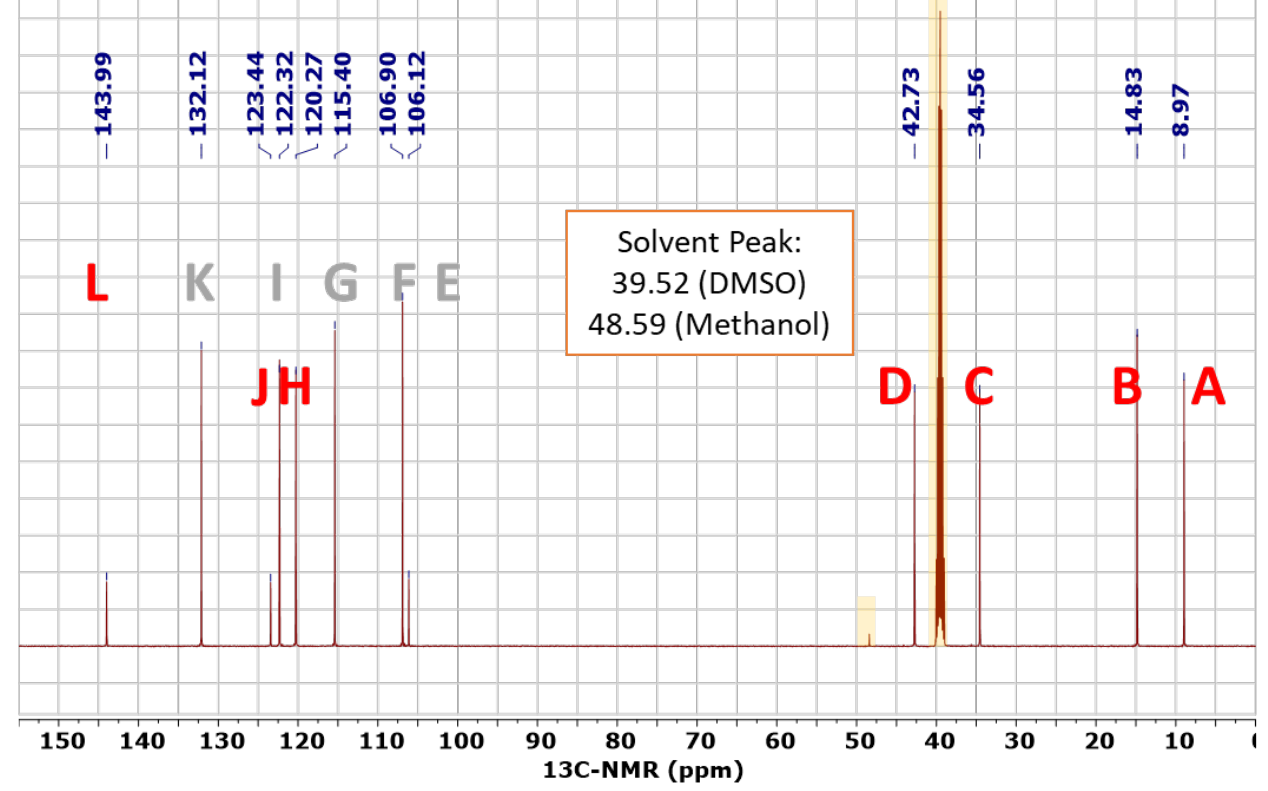

Figure S2. (a) ${ }^{1} \mathrm{H}-\mathrm{NMR}$ and (b) ${ }^{13} \mathrm{C}-\mathrm{NMR}$ of [EMMIM][2-CNpyr]. 


\section{Inverse recovery measurement for the quantification of ${ }^{13} \mathrm{C}$ NMR}

The quantitative analysis of $\mathrm{CO}_{2}$-rIL/DES complex was enabled by setting the time interval (D1) between two successful re-orientation to be longer than 5 times T1, which is the longest spinlattice relaxation time of all $\mathrm{CO}_{2}$ complex, such that signal saturation is avoided. The $\mathrm{T} 1$ relaxation time of different CO2-complex was measured by the inversion recovery approach (Figure S3a): $\left(D 1-180^{\circ}-\tau_{c}-90^{\circ} x-F I D\right)_{n}$, where the $D 1$ in the sequence is estimated to be $4 s, \tau_{c}$ value set to be $0,0.05,0.1,0.2$, and $0.5 \mathrm{~s}$, and $\mathrm{n}$ equals to 2048 scan for good signal to noise $(\mathrm{S} / \mathrm{N})$ ratio, which is also being used to estimate the standard deviation of $\mathrm{T} 1$. The $\mathrm{T} 1$ value of different $\mathrm{CO}_{2}-$ complex is extracted by equation 1 :

$$
M=M_{0}\left(1-2 e^{\left(\frac{-\tau_{c}}{T_{1}}\right)}\right)
$$

where $M$ is the magnetization in the $z$ direction at time $t=\tau_{c}$ and $M_{0}$ is the macroscopic magnetization vector. Figure $\mathbf{S 3 b}$ and Figure $\mathbf{S 3 c}$ shows the obtained ${ }^{13} \mathrm{C}-\mathrm{NMR}$ spectra at different time-delay $\left(\tau_{c}\right)$. 
(a)

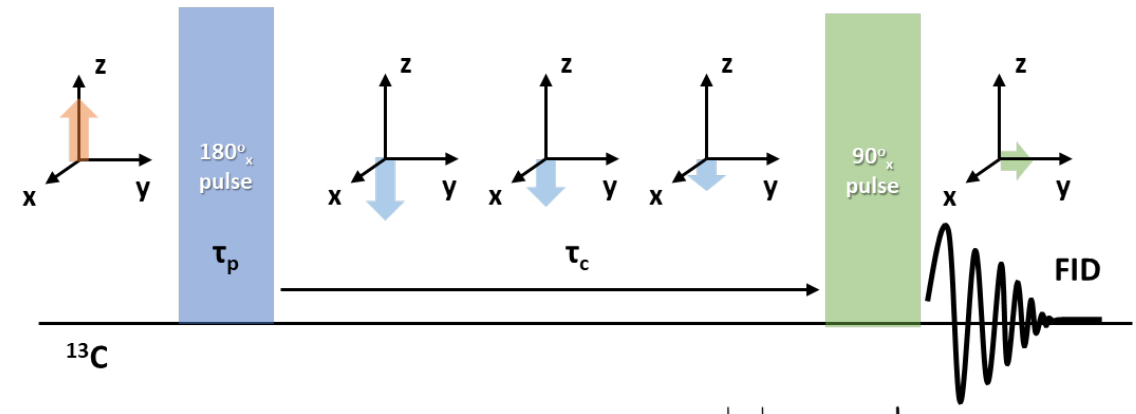

(b)

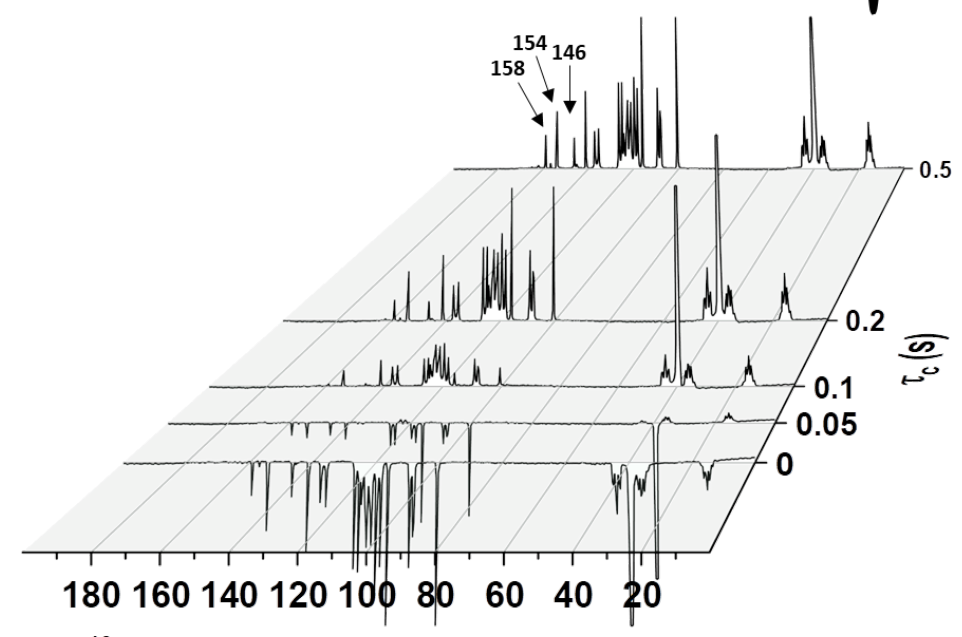

(c)

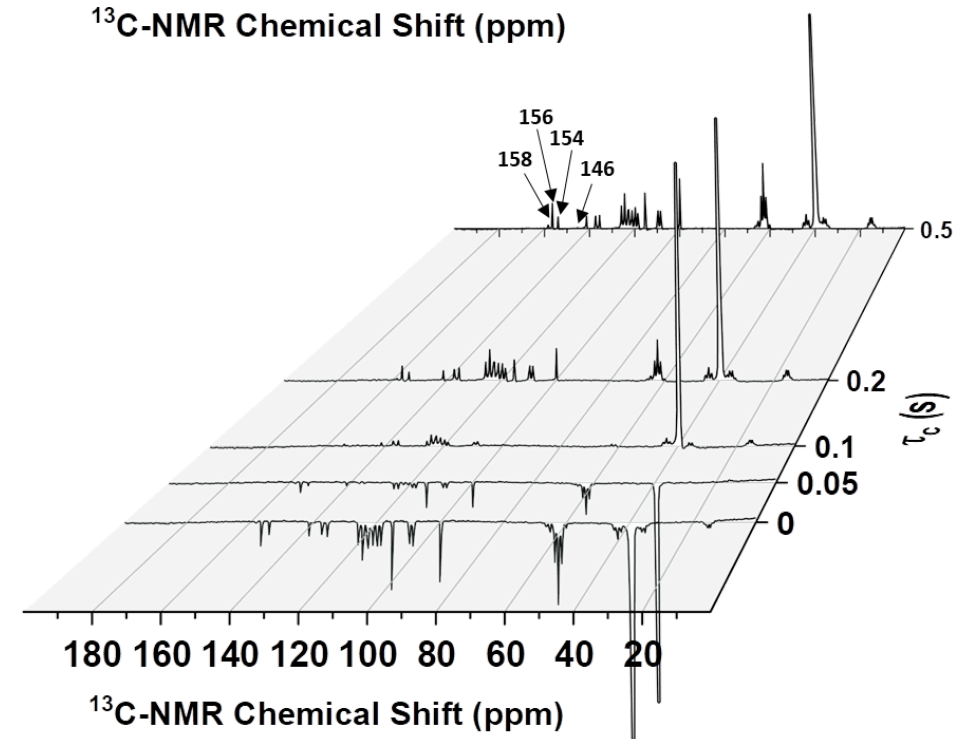

Figure S3. (a) Pulse sequence for determining the ${ }^{13} \mathrm{C}$ T1 (spin-lattice) relaxation time by the inversion recovery approach. (b) $125.75 \mathrm{MHz}{ }^{13} \mathrm{C}-\mathrm{NMR}$ spectra of [EMIM][2-CNpyr]/CO 2 (1bar) sample recorded by the inversion recovery method with $\mathrm{T}_{\mathrm{c}}=0,0.05,0.1,0.2$, and $0.5 \mathrm{~s}$. (c) ${ }^{13} \mathrm{C}$ NMR spectra [EMIM][2-CNpyr]:EG (1:2)/ $/ \mathrm{CO}_{2}$ (1 bar) sample using the same inversion recovery method. 


\section{Measured physical properties and water content of samples}

Excess molar volume $\left(V_{m}^{E}\right)$ calculated from experimental density data by equation 2 :

$V_{m}^{E}=\sum_{i}\left(\frac{1}{\rho}-\frac{1}{\rho_{i}}\right) x_{i} M_{i}$

where $i$ represents a component, $\rho$ is the measured density of the mixture, $\rho_{i}, x_{i}$, and $M_{i}$ are the density, mole fraction, and molar mass of $i$, respectively. The Redlich-Kister fit is the polynomial expansion as expressed in equation 3 :

$V_{m}^{E}=x(1-x) \sum_{i=0}^{j} A_{i}(1-2 x)^{i}$

where $A_{i}$ are the fitting parameters. Since there are only 2 components in the studied solvents ( $\mathrm{rIL}$ and EG); there are three fit parameters and they are evaluated be $-3.883,-4.0129$, and 6.2178 for $A_{0}, A_{1}$ and $A_{2}$, respectively.

Table S1. Density $(\rho)$ and excess molar volume $\left(V_{m}^{E}\right)$ of [EMIM][2-CNpyr]:EG with respect to the mole fraction rIL $\left(\mathrm{X}_{\mathrm{rIL}}\right)$ and mole ratio at $298 \mathrm{~K}$.

\begin{tabular}{|l|l|l|l|}
\hline $\mathbf{X}_{\mathbf{r l L}}$ & Mole ratio (rIL:EG) & $\boldsymbol{\rho}\left(\mathbf{g} / \mathbf{c m}^{\mathbf{3}}\right)$ & $\boldsymbol{V}_{\boldsymbol{m}}^{E}\left(\mathbf{c m}^{\mathbf{3}} / \mathbf{m o l}\right)$ \\
\hline 1 & $1: 0$ & 1.08681 & 0 \\
\hline 0.625 & $1: 0.6$ & 1.10011 & -1.222 \\
\hline 0.5 & $1: 1$ & 1.10117 & -0.995 \\
\hline 0.33 & $1: 2$ & 1.10346 & -0.723 \\
\hline 0.25 & $1: 3$ & 1.10545 & -0.621 \\
\hline 0.2 & $1: 4$ & 1.10714 & -0.578 \\
\hline 0.167 & $1: 5$ & 1.10841 & -0.548 \\
\hline 0.125 & $1: 7$ & 1.10984 & -0.486 \\
\hline 0.091 & $1: 10$ & 1.11103 & -0.427 \\
\hline 0 & $0: 1$ & 1.10976 & 0 \\
\hline
\end{tabular}


Table S2. Measured viscosities $(\mu)$ and densities $(\rho)$ as a function of temperature for [EMIM][2CNpyr]:EG (1:2). VFT fit parameters for the temperature dependence of viscosity $\left(\mu_{0}, E, T_{0}\right)$ and linear fit parameters for the temperature dependence of density $(A$ and $B)$ are listed. The goodness of the fit for the viscosity: $x^{2}=0.85731$.

\begin{tabular}{|c|c|c|c|c|c|c|c|}
\hline$T$ & $\mu$ & \multicolumn{3}{|c|}{$\mu=\mu_{0} \exp \left(\frac{E}{T-T_{0}}\right)$} & $\rho$ & \multicolumn{2}{|c|}{$\rho=A+B \times 10^{-3} T$} \\
\hline$(\mathrm{K})$ & $(\mathrm{cP})$ & $\mu_{0}(\mathrm{cP})$ & $E(\mathrm{~K})$ & $T_{0}(\mathrm{~K})$ & $\left(\mathrm{g} / \mathrm{cm}^{3}\right)$ & $\begin{array}{l}A \\
\left(\mathrm{~g} / \mathrm{cm}^{3}\right)\end{array}$ & $\begin{array}{l}B \times 10^{-3} \\
(1 / \mathrm{K})\end{array}$ \\
\hline 298 & 50.15 & \multirow{7}{*}{0.04899} & \multirow{7}{*}{904.62} & \multirow{7}{*}{165.54} & 1.10413 & \multirow{7}{*}{1.12135} & \multirow{7}{*}{-0.69} \\
\hline 303 & 41.20 & & & & 1.10074 & & \\
\hline 308 & 33.25 & & & & 1.09731 & & \\
\hline 313 & 27.46 & & & & 1.09385 & & \\
\hline 318 & 23.62 & & & & 1.09037 & & \\
\hline 323 & 19.67 & & & & 1.08691 & & \\
\hline 328 & 17.16 & & & & 1.08348 & & \\
\hline
\end{tabular}

Table S3. Moisture content and viscosity of [EMIM][2-CNpyr] and [EMIM][2-CNpyr]:EG (1:2) after $\mathrm{CO}_{2}$ absorption. The viscosity and water content 'prior to $\mathrm{CO}_{2}$ ' were measured right after the sample was prepared in an Argon-filled glovebox. The viscosity of [EMIM][2-CNpyr] is in good agreement with our previous report with a different batch of rIL. The reported uncertainties were determined from three repeated measurements.

\begin{tabular}{|c|c|c|c|c|}
\hline & \multicolumn{2}{|c|}{ [EMIM][2-CNpyr] } & \multicolumn{2}{|c|}{ [EMIM][2-CNpyr]:EG (1:2) } \\
\hline & $\mu(\mathrm{cP})$ at $25^{\circ} \mathrm{C}$ & ppm $\mathrm{H}_{2} \mathrm{O}$ & $\mu(\mathrm{cP})$ at $25^{\circ} \mathrm{C}$ & ppm $\mathrm{H}_{2} \mathrm{O}$ \\
\hline Prior to $\mathrm{CO}_{2}$ & $67.8 \pm 0.2$ & $900 \pm 200$ & $45.1 \pm 0.2$ & $793 \pm 230$ \\
\hline $410 \mathrm{ppm} \mathrm{CO}_{2}$ in $\mathrm{N}_{2}$ & $\mathrm{~N} / \mathrm{A}$ & $\mathrm{N} / \mathrm{A}$ & $57.8 \pm 0.2$ & $1420 \pm 120$ \\
\hline 2000 ppm $\mathrm{CO}_{2}$ in $\mathrm{N}_{2}$ & $\mathrm{~N} / \mathrm{A}$ & $4,800 \pm 350$ & $68.3 \pm 0.4$ & $880 \pm 180$ \\
\hline $5000 \mathrm{ppm} \mathrm{CO}$ in $\mathrm{N}_{2}$ & $\mathrm{~N} / \mathrm{A}$ & $5,400 \pm 360$ & $78.1 \pm 0.4$ & $1,570 \pm 390$ \\
\hline Dry $\mathrm{CO}_{2}$ (1 bar) & $247.2 \pm 3.6$ & $4,900 \pm 260$ & $88.2 \pm 1.5$ & $2,780 \pm 380$ \\
\hline $\begin{array}{l}\text { Moist } \mathrm{CO}_{2} \\
\text { (1 bar, } 100 \% \mathrm{RH})\end{array}$ & $\mathrm{N} / \mathrm{A}$ & $\begin{array}{l}334,400 \pm \\
27,500\end{array}$ & $N / A$ & $\begin{array}{l}375,248 \pm \\
11,000\end{array}$ \\
\hline
\end{tabular}




\section{FTIR spectra of [EMIM][2-CNpyr] before and after $\mathrm{CO}_{2}$ absorption}

The analysis of the IR spectra for the rIL:EG (1:2) after $\mathrm{CO}_{2}$ absorption as seen in Figure S4a. The resonance signals of carbamate and carboxylate are observed at around $1400 \mathrm{~cm}^{-1}\left(\mathrm{~V}_{\mathrm{C}-\mathrm{N}}\right.$ and $\mathrm{V}_{\mathrm{C}-\mathrm{C}}$ ). The peaks at $1050 \mathrm{~cm}^{-1}$ ( $\left.\mathrm{V}_{\mathrm{C}-\mathrm{O}-(\mathrm{COO})}\right)$ and $1280 \mathrm{~cm}^{-1}$ ( $\left.\mathrm{V}_{\mathrm{O}-(\mathrm{COO})}\right)$ are assigned to newly formed carbonate, and the peak at $1600 \mathrm{~cm}^{-1}\left(\mathrm{~V}_{\mathrm{as}}, \mathrm{c}=0\right)$ is a combination of carbamate, carboxylate, carbonate, and possibly bicarbonate (due to residual water) where deconvolution is challenging because of the hydrogen bonding network among these groups. The hydroxyl ( $\left.v_{\mathrm{O}-\mathrm{H}}\right)$ resonance peak at $3360 \mathrm{~cm}^{-1}$ broadens and redshifts as the concentration of $\mathrm{CO}_{2}$ in the feed increases, indicating the formation of a H-bond network between rIL and EG. Additionally, the amine $\left(\mathrm{V}_{\mathrm{N}-\mathrm{H}}\right)$ of the protonated pyrrolide anion contributes to this broad resonance signal. The stretching mode of the cyano group $\left(\mathrm{v}_{\mathrm{C} \equiv \mathrm{N}}\right)$ on the anion shows a split due to the protonation of the anion and the associated $\mathrm{H}$-bonding. Likewise, the spectra of neat $\mathrm{rlL}$ before and after reaction with $\mathrm{CO}_{2}$ in Figure S4b is consistent with the carbamate $\left(\mathrm{V}_{\mathrm{C}-\mathrm{N}}: 1320 \mathrm{~cm}^{-1}\right.$ and $\left.\mathrm{V}_{\mathrm{as}}, \mathrm{N}-(\mathrm{C}=0): 1620 \mathrm{~cm}^{-1}\right)$ and carboxylate ( $\mathrm{v}_{\mathrm{c}-\mathrm{c}}: 1370 \mathrm{~cm}^{-1}$ and $\left.\mathrm{V}_{\mathrm{as}}, \mathrm{C}-(\mathrm{C}=0): 1710 \mathrm{~cm}^{-1}\right)$ formations. Both Figure S4a and Figure S4b shows that the anion peak at $2180 \mathrm{~cm}^{-1}$ diminishes and the peak at $2220 \mathrm{~cm}^{-1}$ intensifies as more $\mathrm{CO}_{2}$ is absorbed. 

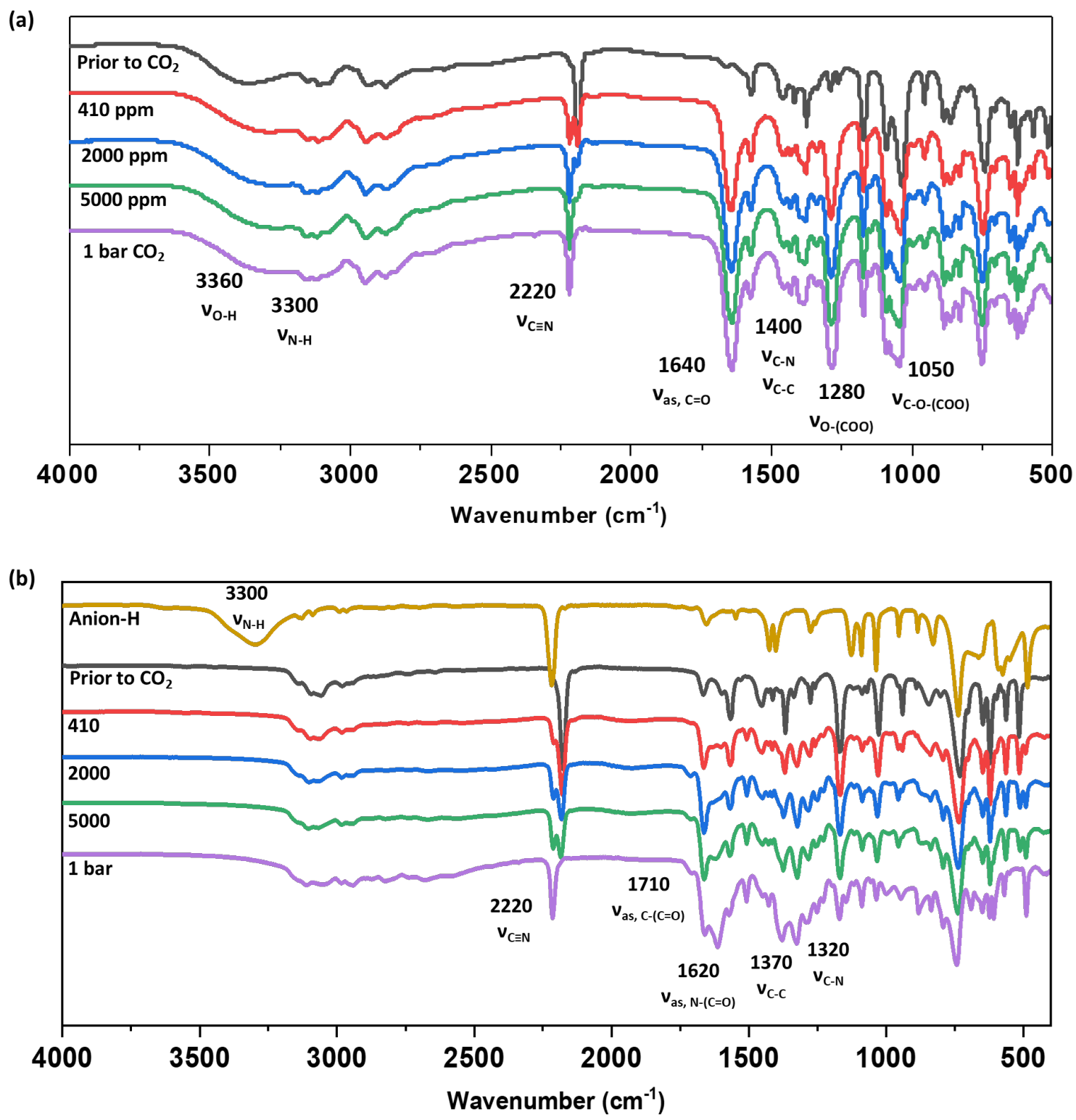

Figure S4. (a) ATR-FTIR spectra of [EMIM][2-CNpyr]:EG (1:2) prior to and after $\mathrm{CO}_{2}$ absorption

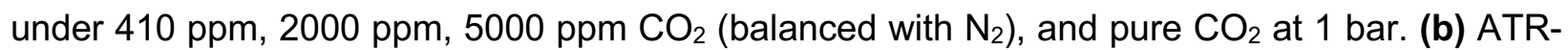
FTIR spectra of pyrrole-2-carbonotrile (anion-H) and [EMIM][2-CNpyr] before and after $\mathrm{CO}_{2}$ absorption at $410 \mathrm{ppm}, 2000 \mathrm{ppm}$, and $5000 \mathrm{ppm}$ of $\mathrm{CO}_{2}$ (balanced with $\mathrm{N}_{2}$ ), and pure $\mathrm{CO}_{2}$ at 1 bar. Water contents after $\mathrm{CO}_{2}$ absorption are provided in Table $\mathbf{S 3}$. 
Comparison of $\mathrm{CO}_{2}$ capacity of [EMIM][2-CNpyr] and [EMMIM][2-CNpyr]

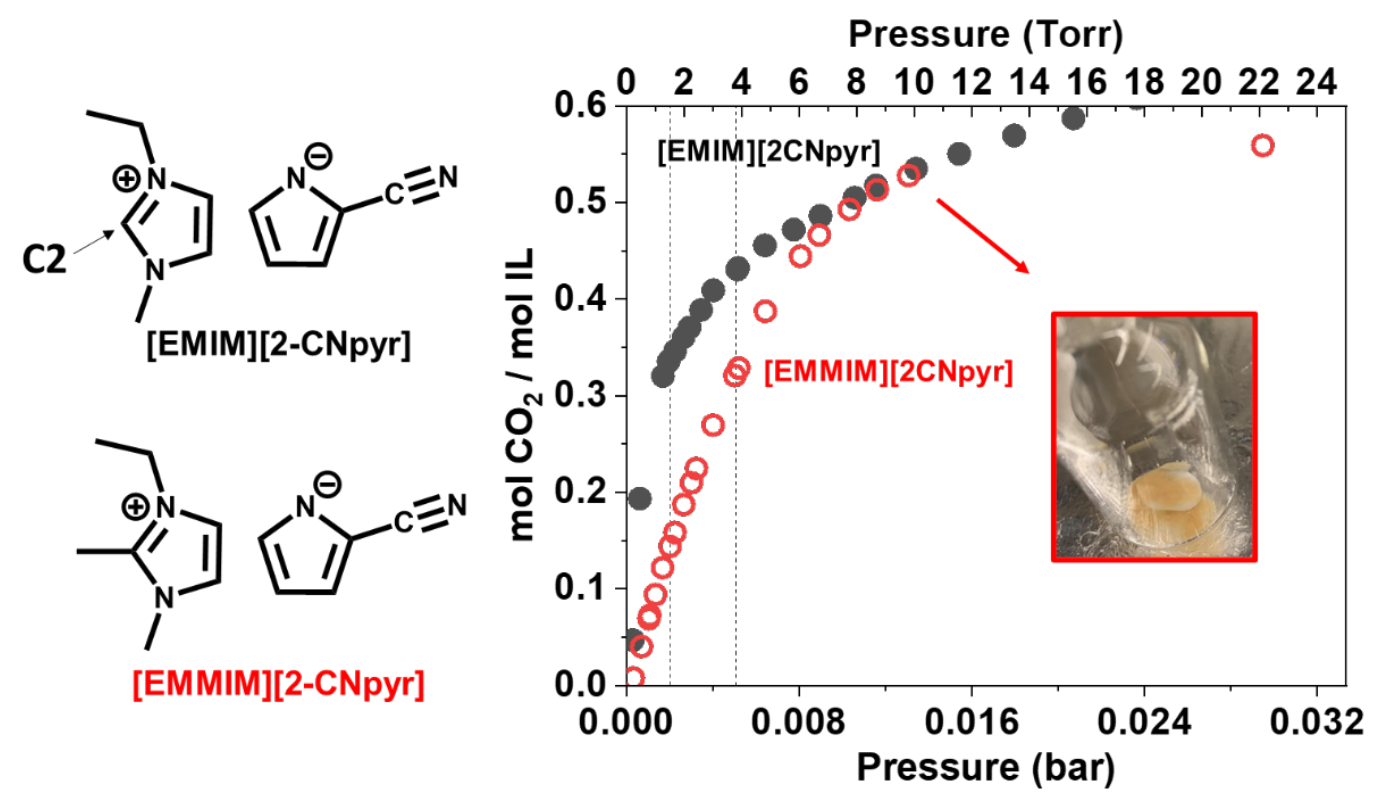

Figure S5. $\mathrm{CO}_{2}$ absorption capacity of [EMIM][2-CNpyr] and [EMMIM][2-CNpyr]. C2 position is shown in the chemical structure on the left. Inset photo shows the solidification of [EMMIM][2CNpyr] at 10 Torr (0.013 bar). The sluggish absorption rate after this solidification causes a big gap before the next data point. 


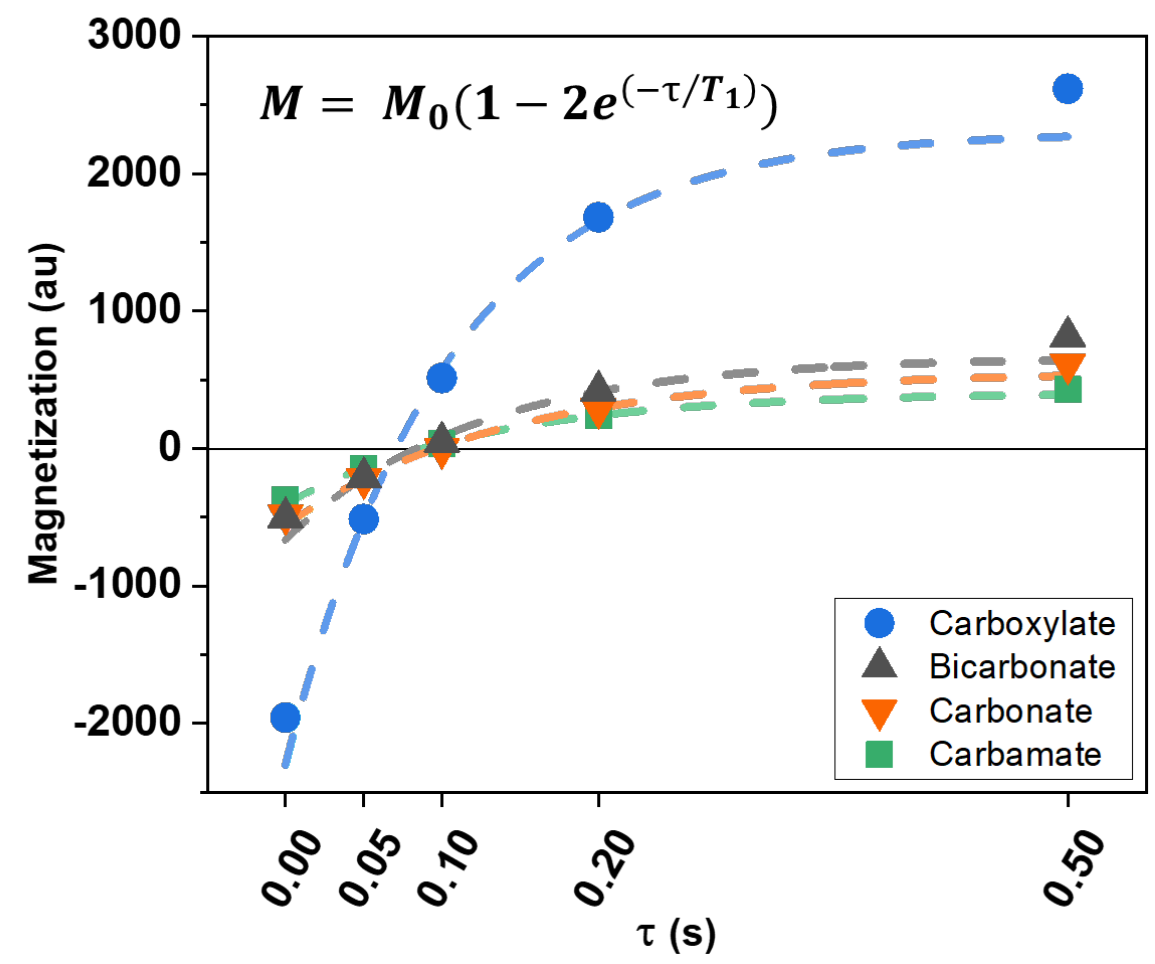

Figure S6. Evolution with time of the longitudinal component $\mathrm{M}_{z}$ after a $180^{\circ}$ x pulse. The delay time $\mathrm{T}$ between $180^{\circ} \mathrm{x}$ and $90^{\circ} \mathrm{x}$ was set to be $0,0.05,0.1,0.2,0.5 \mathrm{~s}$. The assignments of four signals (carbamate 146 ppm, carboxylate 154 ppm, carbonate 156 ppm, and bicarbonate 158 ppm) in different chemical environment $C$ nuclei are shown. T1, the spin-lattice relaxation is acquired by fitting the magnetization (M) with respect to time (т). $M$ is the magnetization in the $z$ direction at time $t=T$ and $M_{0}$ is the macroscopic magnetization vector. The extracted $T 1$ value is given in Table S4.

Table S4. The T1 value of C nuclei in carbamate (146 ppm), carboxylate (154 ppm), carbonate (156 ppm), and bicarbonate (158 ppm). The uncertainty of T1 is calculated by the S/N ratio to be $<0.01$ s.

\begin{tabular}{|l|l|l|l|l|}
\hline & Carbamate & Carboxylate & Bicarbonate & Carbonate \\
\hline T1 (s) & 0.13 & 0.10 & 0.12 & 0.13 \\
\hline
\end{tabular}


Quantitative ${ }^{13} \mathrm{C}-\mathrm{NMR}$ spectra of [EMIM][2-CNpyr] after $\mathrm{CO}_{2}$ absorption

(a)

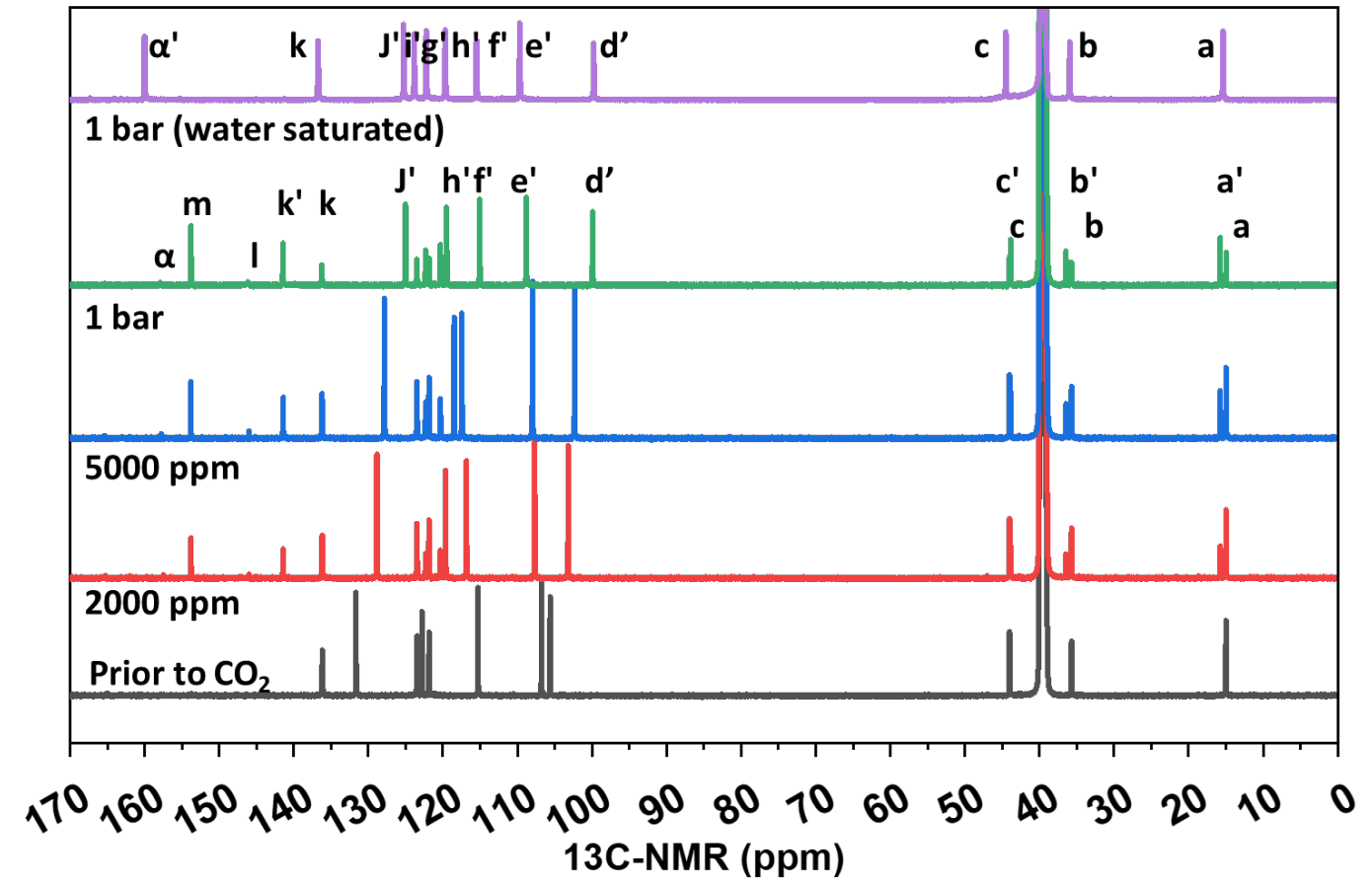

(b)

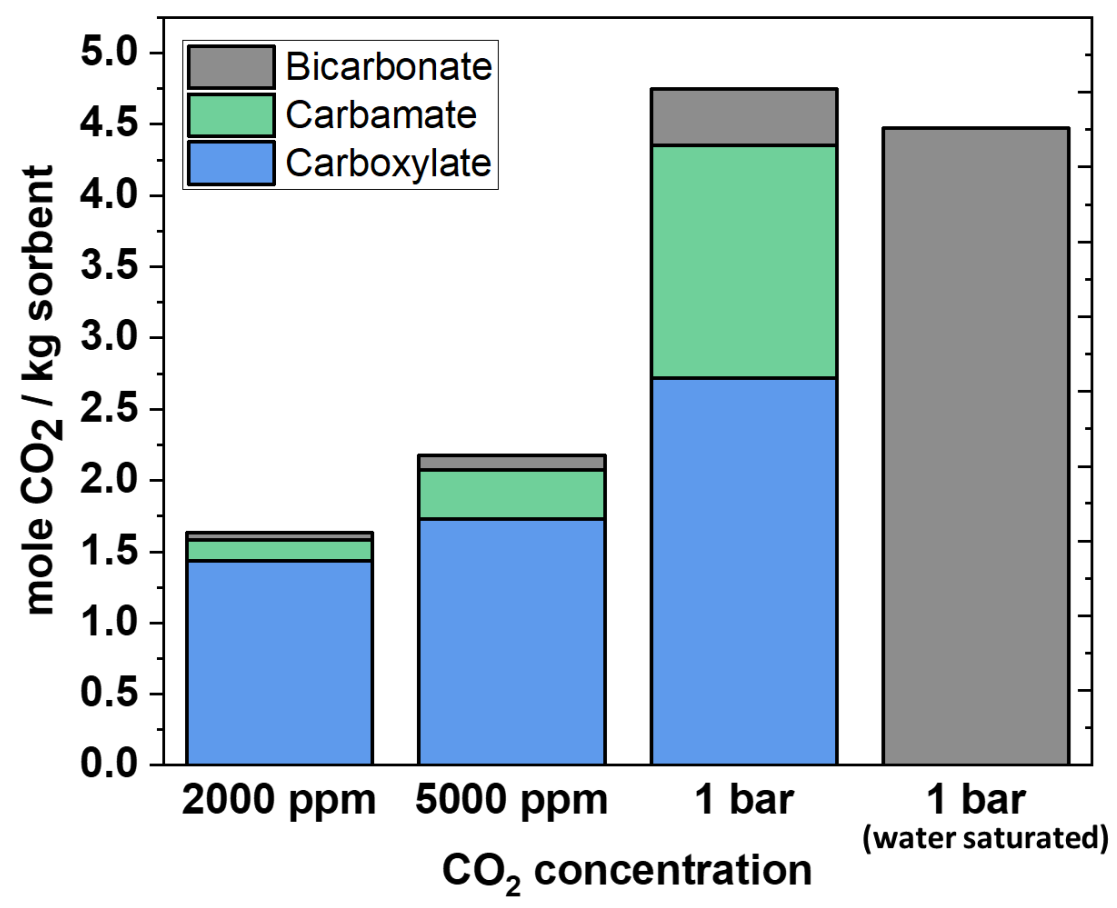

Figure S7. Quantitative ${ }^{13} \mathrm{C}-\mathrm{NMR}$ spectra. (a) [EMIM][2-CNpyr] before and after $\mathrm{CO}_{2}$ absorption under different concentration. The integral values of all peaks are normalized by the "d" position $\mathrm{C}$ on the anion. The formation of bicarbonate (158 ppm) in rlL after 2000 ppm, 5000 ppm, and 1 
bar $\mathrm{CO}_{2}$ absorption is due to the uptake moisture while performing the weighing method. The bicarbonate peak further downshifts to around $160 \mathrm{ppm}$ in rlL when purged with water saturated $\mathrm{CO}_{2}$, suggesting a different $\mathrm{H}$-bond system in water-rich environment. (b) The breakdown $\mathrm{CO}_{2}$ capacity of carboxylate, carbamate, and bicarbonate rIL as a function of $\mathrm{CO}_{2}$ concentration and moisture content.

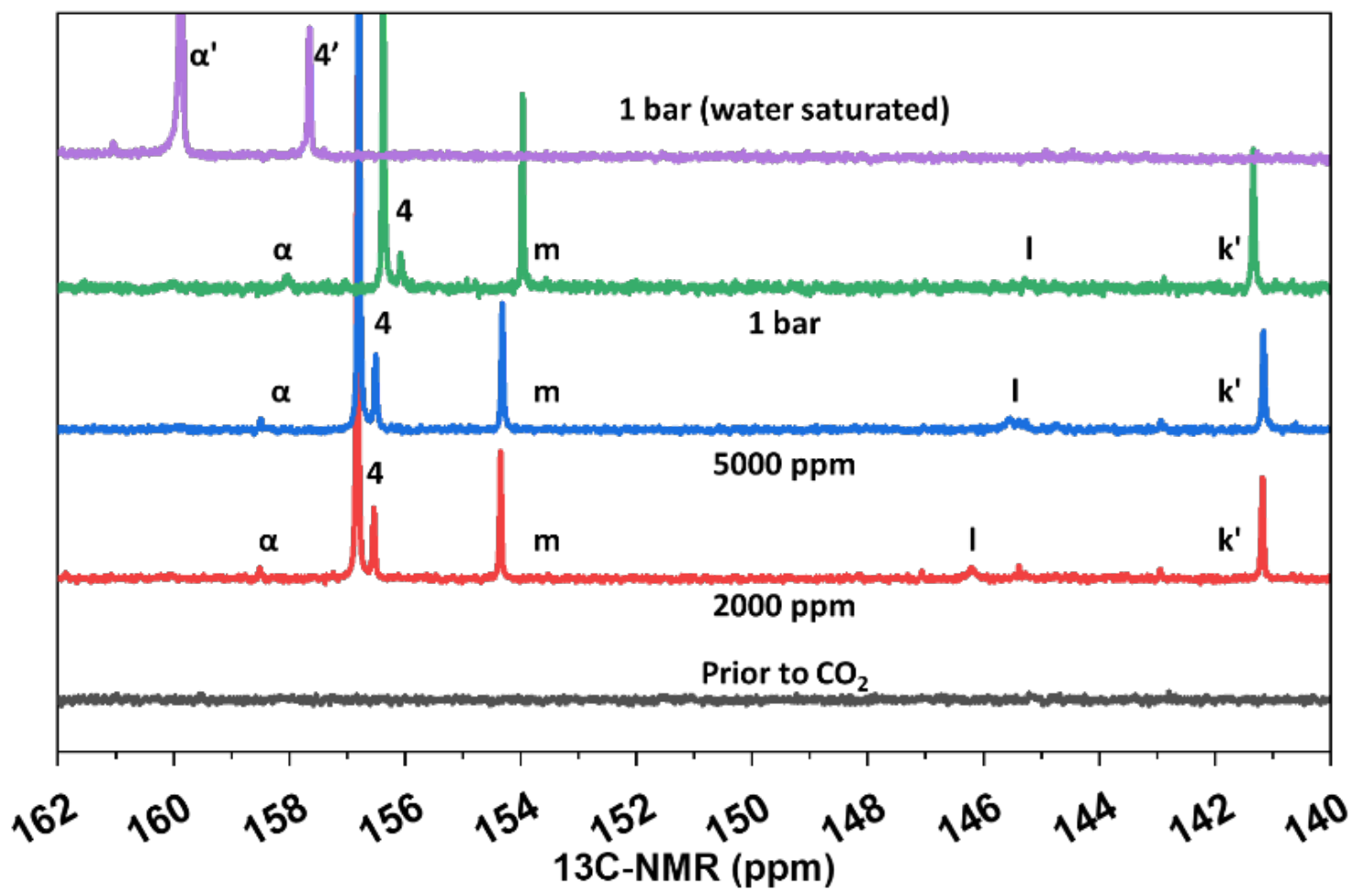

Figure S8. Zoomed-in plot of quantitative ${ }^{13} \mathrm{C}-\mathrm{NMR}$ spectra of 1:2 rlL:EG before and after $\mathrm{CO}_{2}$ absorption under different concentration, highlighting the carbamate peak in the vicinity of 146 ppm. Notice that peaks slightly shift due to the influence of $\mathrm{H}$-bond system. 
(a)
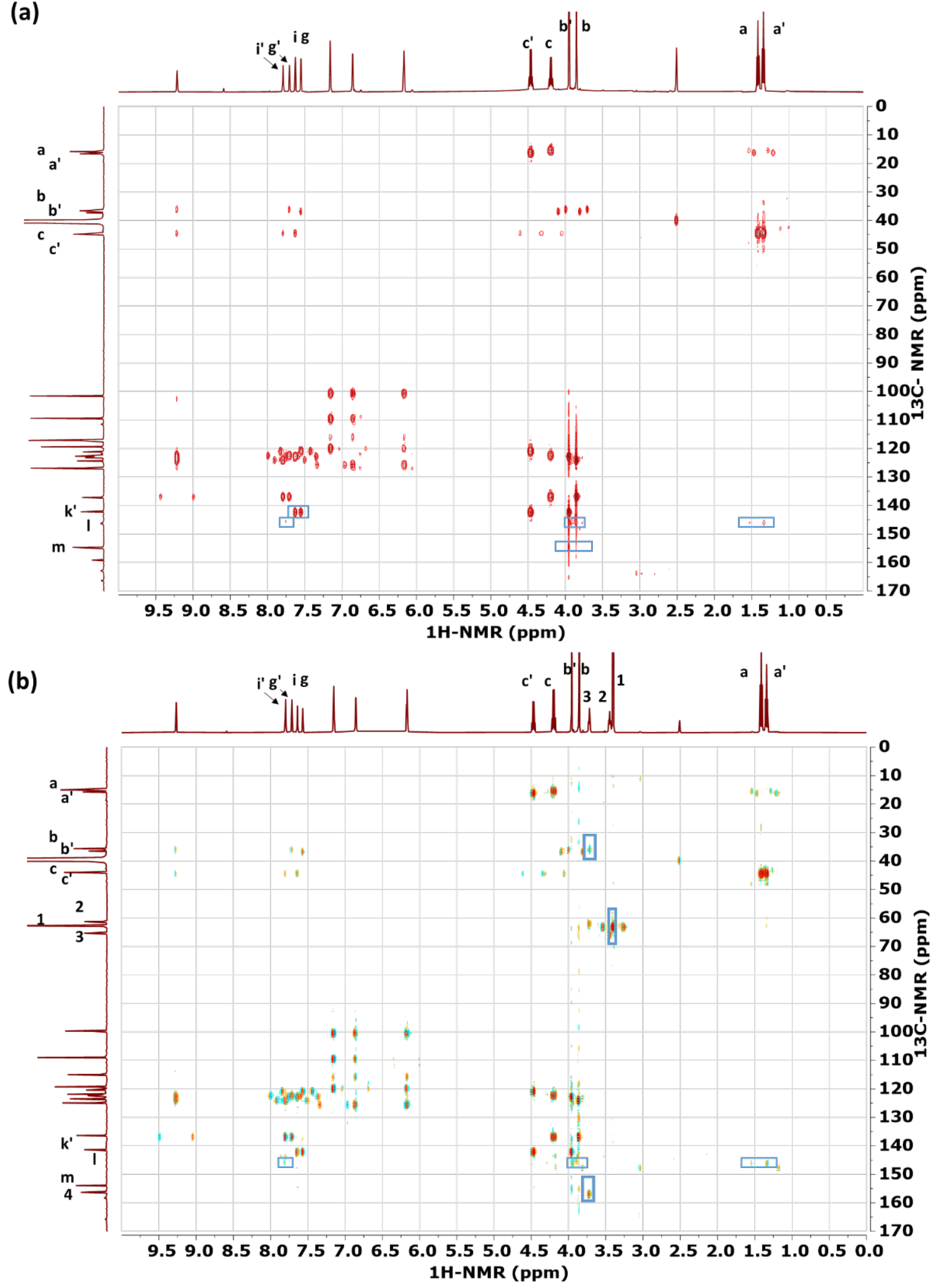

Figure S9. HMBC spectra of (a) [EMIM][2-CNpyr] (rIL) and (b) 1:2 rlL:EG after $\mathrm{CO}_{2}$ absorption (1 bar of dry $\mathrm{CO}_{2}$ ) with DMSO- $\mathrm{d}_{6}$, where correlations between $\mathrm{C}$ and $\mathrm{H}$ separated by two or three 
bonds are targeted. The boxed correlation peaks in panel (a) show the coupling between $\mathrm{C}$ peak at 141 ppm (k') and $\mathrm{H}$ peak at $7.6 \mathrm{ppm}$ (g and i); between C peak at 146 ppm (I) and $\mathrm{H}$ peaks at 1.5 ppm (a and a'), 4 ppm (b and b'), and 7.8 ppm (g' and i'); between C peak at 154 ppm (m) and $\mathrm{H}$ peak at 4 ppm ( $\mathrm{b}$ and $\mathrm{b}^{\prime}$ ). These correlations confirm the interactions between the cation and the anion. The boxes in panel (b) highlight the coupling between $\mathrm{C}$ peak at $35 \mathrm{ppm}$ (b') and $\mathrm{H}$ peaks at 3.7 ppm (3); between $\mathrm{C}$ peak at $62 \mathrm{ppm}$ (2 and 3) and proton peaks at $3.4 \mathrm{ppm}$ (1); between $\mathrm{C}$ peak at 146 ppm (I) and $\mathrm{H}$ peak at 1.5 ppm (a and a'), 3.9 ppm (b and b'), 7.8 ppm (g' and i'); between the $\mathrm{C}$ peak at $158 \mathrm{ppm}(\mathrm{m})$ and $\mathrm{H}$ peak $3.7 \mathrm{ppm}$ (3). These correlations demonstrate the interaction between all cation, anion, and EG.

Table S5. Integral values for the carbamate (route 1), carboxylate (route 2), carbonate (route 3) and bicarbonate (route 4) peaks in ${ }^{13} \mathrm{C}$ NMR shown in Figure 4 due to complexation of $\mathrm{CO}_{2}$ with the anion, cation, deprotonated EG, and water, respectively. The NMR peak of the anion (d) was set to 1 therefore, the integral values, $n$, are given per anion: \# of $n$ / \# of anion. This is equivalent to number of moles of $\mathrm{CO}_{2}$ per mole of rlL. The contribution of each route to the overall $\mathrm{CO}_{2}$ capacity is provided in terms of percentages in parenthesis. The molecular weight of the DES is: $326.4 \mathrm{~g} / \mathrm{mol}(\mathrm{IL}+2 \mathrm{EG})$.

\begin{tabular}{|c|c|c|c|c|c|}
\hline \multicolumn{6}{|l|}{ [EMIM][2-CNpyr] } \\
\hline & $\begin{array}{l}\text { Carbamate } \\
146 \text { ppm }\end{array}$ & $\begin{array}{l}\text { Carboxylate } \\
154 \text { ppm }\end{array}$ & $\begin{array}{l}\text { Carbonate } \\
156 \text { ppm }\end{array}$ & $\begin{array}{l}\text { Bicarbonate } \\
158 \text { ppm }\end{array}$ & Total \\
\hline & \multicolumn{5}{|c|}{ \# of $\mathrm{n} / \mathrm{\#}$ of anion ( $\% \mathrm{CO}_{2}$ capacity) } \\
\hline $2000 \mathrm{ppm} \mathrm{CO}_{2}$ in $\mathrm{N}_{2}$ & $0.03(9.1)$ & $0.29(87.9)$ & - & $0.01(3.0)$ & $0.33(100)$ \\
\hline $5000 \mathrm{ppm} \mathrm{CO}_{2}$ in $\mathrm{N}_{2}$ & $0.07(15.9)$ & $0.35(79.5)$ & - & $0.02(4.5)$ & $0.44(100)$ \\
\hline Dry $\mathrm{CO}_{2}$ (1 bar) & $0.33(34.4)$ & $0.55(57.3)$ & - & $0.08(8.3)$ & $0.96(100)$ \\
\hline $\begin{array}{l}\text { Moist } \mathrm{CO}_{2}(1 \text { bar, } \\
100 \% \mathrm{RH})\end{array}$ & - & - & - & $1.02(100)$ & $1.02(100)$ \\
\hline \multicolumn{6}{|c|}{ [EMIM][2-CNpyr]:EG (1:2) } \\
\hline & $\begin{array}{l}\text { Carbamate } \\
146 \text { ppm }\end{array}$ & \begin{tabular}{|l} 
Carboxylate \\
154 ppm
\end{tabular} & $\begin{array}{l}\text { Carbonate } \\
156 \text { ppm }\end{array}$ & $\begin{array}{l}\text { Bicarbonate } \\
158 \mathrm{ppm}\end{array}$ & Total \\
\hline & \multicolumn{5}{|c|}{ \# of $\mathrm{n} / \mathrm{\#}$ of anion (\% $\mathrm{CO}_{2}$ capacity) } \\
\hline $2000 \mathrm{ppm} \mathrm{CO}_{2}$ in $\mathrm{N}_{2}$ & $0.03(4.1)$ & $0.12(16.4)$ & $0.57(78.1)$ & $0.01(1.4)$ & $0.73(100)$ \\
\hline $5000 \mathrm{ppm} \mathrm{CO}_{2}$ in $\mathrm{N}_{2}$ & $0.06(7.3)$ & $0.14(17.1)$ & $0.61(74.4)$ & $0.01(1.2)$ & $0.82(100)$ \\
\hline Dry $\mathrm{CO}_{2}$ (1 bar) & $0.02(2.3)$ & $0.26(29.9)$ & $0.58(66.7)$ & $0.01(1.1)$ & $0.87(100)$ \\
\hline $\begin{array}{l}\text { Moist } \mathrm{CO}_{2}(1 \text { bar, } \\
100 \% \mathrm{RH})\end{array}$ & - & - & $0.18(18.0)$ & $0.82(82.0)$ & $1.00(100)$ \\
\hline
\end{tabular}


Table S6. Calculated energies for reactant systems, transition states (TS), and products for the proposed reaction routes; accounting for the hydrogen bonding. $\Delta \boldsymbol{E}$ is the reaction energy (products minus reactants), $\boldsymbol{E}_{\boldsymbol{a}}$ is the activation energy (TS minus reactants), and $\mathrm{k}$ is the reaction rate constant in $\left(\mathrm{cm}^{3} /\right.$ molecule/s). The $\mathrm{CO}_{2}$ binding is represented with $\cdots$ while hydrogen gain or loss are represented with + or - . Superscripts indicate the charge. Routes 2 has two transition states (TS2* and TS2 ${ }^{* *}$ ) with a carbene intermediate. The difference in route 1 and 2 reactants is the placement of $\mathrm{CO}_{2}$; one closer to the anion (1) and the other closer to the cation (2).

\begin{tabular}{|c|c|c|c|c|c|c|}
\hline Route & & & $\begin{array}{l}\text { E } \\
\text { (Hartrees) }\end{array}$ & $\begin{array}{l}E_{a} \\
(\mathrm{~kJ} / \mathrm{mol})\end{array}$ & $\begin{array}{l}\Delta E \\
(\mathrm{~kJ} / \mathrm{mol})\end{array}$ & $\begin{array}{l}\mathbf{k} \\
\times 10^{7}\end{array}$ \\
\hline \multirow{3}{*}{1} & Products & {$\left[_{\mathrm{EMIM}}\right]^{+}+\left[2 \mathrm{CNpyr} \cdots \mathrm{CO}_{2}\right]^{-}$} & -834.7466 & & \multirow{3}{*}{-18.36} & \multirow{3}{*}{2.513} \\
\hline & & TS1 & -834.7373 & 6.18 & & \\
\hline & Reactants & {$\left[\mathrm{EMIM}^{+}+[2 \mathrm{CNpyr}]^{-}+\mathrm{CO}_{2}\right.$} & -834.7396 & & & \\
\hline \multirow{5}{*}{2} & Products & {$\left[\mathrm{EMIM} \cdots \mathrm{CO}_{2}\right]+[2 \mathrm{CNpyr}+\mathrm{H}]$} & -834.7582 & & \multirow{5}{*}{-69.25} & \\
\hline & & $\mathrm{TS}^{* *}$ & -834.7337 & 10.73 & & 2.509 \\
\hline & Intermediate & {$[\mathrm{EMIM}-\mathrm{H}]+[2 \mathrm{CNpyr}+\mathrm{H}]+\mathrm{CO}_{2}$} & -834.7378 & & & \\
\hline & & $\mathrm{TS}^{*}$ & -834.7295 & 5.91 & & 2.514 \\
\hline & Reactants & {$[\mathrm{EMIM}]^{+}+[2 \mathrm{CNpyr}]^{-}+\mathrm{CO}_{2}$} & -834.7318 & & & \\
\hline \multirow{3}{*}{3} & Products & {$\left[\mathrm{EG} \cdots \mathrm{CO}_{2}\right]^{-}+[2 \mathrm{CNpyr}+\mathrm{H}]$} & -720.3559 & & \multirow{3}{*}{-16.00} & \multirow{3}{*}{2.517} \\
\hline & & TS3 & -720.3488 & 2.63 & & \\
\hline & Reactants & $\mathrm{EG}+\left[2 \mathrm{CNpyr}^{-}+\mathrm{CO}_{2}\right.$ & -720.3498 & & & \\
\hline
\end{tabular}

Table S7. Calculated energies for individual reactant and product species without hydrogen bonding. Using these values, the $\mathrm{CO}_{2}$ binding to $\mathrm{rlL}$ anion is calculated as $-70 \mathrm{~kJ} / \mathrm{mol} ; \mathrm{CO}_{2}$ binding to the $\mathrm{rlL}$ cation with anion protonation is $-404 \mathrm{~kJ} / \mathrm{mol}$; $\mathrm{CO}_{2}$ binding to $\mathrm{EG}$ with anion protonation is $-57 \mathrm{~kJ} / \mathrm{mol}$.

\begin{tabular}{|l|c|c|c|}
\hline \multicolumn{4}{|c|}{ Individual Reactant Energies } \\
\hline $\mathrm{CO}_{2}$ & {$[2 \mathrm{CNpyr}]^{-}$} & {$[\mathrm{EMIM}]^{+}$} & $\mathrm{EG}$ \\
\hline-188.473 & -301.705 & -344.389 & -230.1052 \\
\hline \multicolumn{4}{|c|}{ Individual Products Energies } \\
\hline$\left[2 \mathrm{CNpyr} \cdots \mathrm{CO}_{2}\right]^{-}$ & {$[2 \mathrm{CNpyr}+\mathrm{H}]$} & {$\left[\mathrm{EG} \cdots \mathrm{CO}_{2}\right]^{-}$} & {$\left[\mathrm{EG} \cdots \mathrm{CO}_{2}\right]^{-}$} \\
\hline-490.205 & -302.271 & -532.452 & -418.035 \\
\hline
\end{tabular}

